\title{
Assessing India's Innovation Ecosystem: The Case Study of Gujarat
}

Myles Elledge, Jamie Jones, and Moline Pandiyan

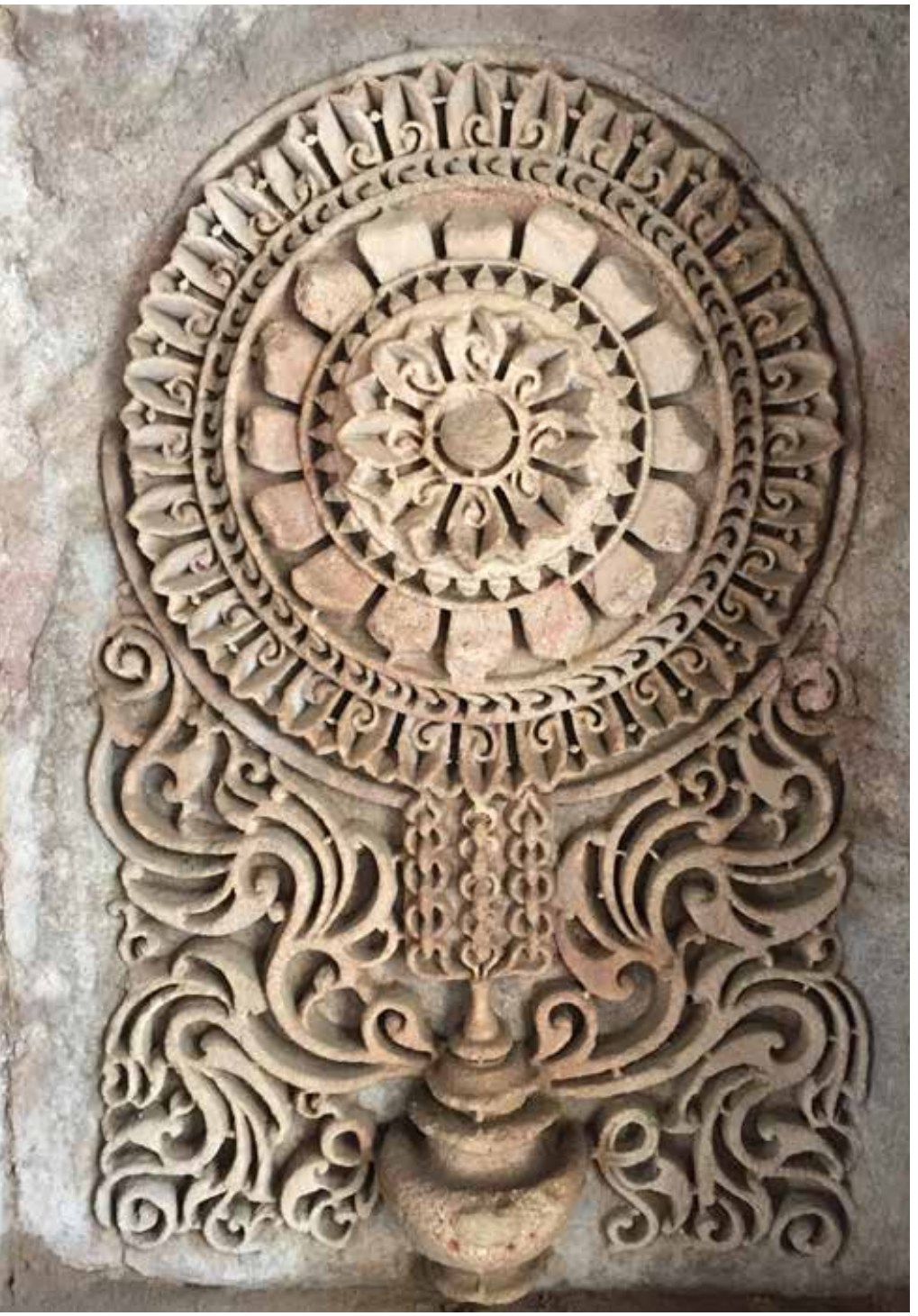

This is an image of a stone carving from the Adalaj Step Well in Gandhinagar (Gujarat). Built in 1499, the Adalaj Step Well is significant as an innovation for accessing and housing water in the five-story structure. An ancient innovation for managing water in semi-arid climate, and the stones provided a cooling effect for those that came to collect and use water from the well.
India plays an increasingly important role in global economic growth as one of the fastest growing economies in the world. India is projected to be the world's most populated country by 2025 , when the population is projected to reach 1.6 billion people, with nearly half under the age of $25{ }^{1}$ The sheer size

\section{Key Findings}

- India ranks low on global scales for innovation and for levels of public and private-sector R\&D investment.

- The State of Gujarat, like much of India, has a trading and industrial assembly oriented economy and lacks a track record of applied research and innovative product development.

- Gujarat's primary and secondary education system is weak relative to its strong infrastructure base and economic strengths, creating workforce development challenges.

- Gujarat has many key assets to build a vibrant innovation ecosystem, including strong universities, a depth of industry, and strong government, although the weak linkages across sectors impede knowledgesector development.

- Deliberate fostering of collaboration between industry and the university sector through government science and technology financing will accelerate applied R\&D.

- Targeting industry cluster development in areas such as energy, engineering materials, agriculture, pharmaceuticals, and biotechnology builds on assets in Gujarat.

- Industry product development is often capital intensive and takes time to sustain through prototype development cycles. Longer-term tax incentives and expanded seed funding schemes will assist with proofof-concept, prototyping, and product development. 
of the population, the growing consumer class and their demand for goods and services, and the transition from a commodities- and trade-based economy to a knowledge-based economy are key forces to power India's continued economic ascent.

For India to transition to a knowledge-based economy, it will need to better harness and direct its science and technology (S\&T) talents. ${ }^{2}$ India ranked 76 out of 143 economies in the Global Innovation Index 2014. ${ }^{3}$ Currently, government-funded research and research institutions are not well aligned with the market, intellectual property (IP) and patent generation are low, and corporate research and development (R\&D) spending is far below industry peers in developed economies. ${ }^{4}$

This research brief presents observations from RTI's market research and key informant interviews to complete an assessment of the innovation ecosystem in the State of Gujarat, which serves as a case study for emerging India. The research focused on understanding the interplay between the public, private, and university sectors for fostering collaboration in $\mathrm{R} \& \mathrm{D}$ and innovation, which is a key development driver of a knowledge-based economy. Gujarat was selected as the focus because it serves as a hub of industrial and economic growth in India. Gujarat's promising but perceived weak R\&D activity and $R \& D$ infrastructure, emerging yet immature start-up culture, business-friendly government, low primary and secondary education achievement, and nationally recognized higher education institutions provide a dynamic opportunity for improvement and growth in India. ${ }^{5}$

Gujarat is noted for its merchant business and trading culture that has been built on the state's large resource base, long coastline, and supportive infrastructure. ${ }^{6}$ Gujarat is among the top five states in India in terms of wealth and gross domestic product (GDP), and it has a broad and large industry sector that includes agriculture, textiles, chemicals, energy, pharmaceuticals, biotechnology, and emerging automotive and aerospace. ${ }^{7}$ The State of Gujarat has over 35 specialized $\mathrm{R} \& \mathrm{D}$ institutes, but stakeholders confirm that there is limited translational research conducted. ${ }^{8}$ To transition from a tradebased economy to a more knowledge-based industrial makeup, Gujarat's industries will need to advance from assembly and value engineering to develop innovative new products and technology. Gujarat has important elements of an innovation ecosystem, including research universities, vocational training of a technical workforce, and a robust base of leading industry players generating wealth.

\section{Methods}

The assessment used the innovation ecosystem assessment (IEA) framework (Figure 1) developed by RTI and applied in several of RTI's client-funded programs to understand supply-and-demand dynamics around innovation, as well as the interaction across the public, private, and university sectors. 9 The assessment, as applied, focuses on a defined geography, the State of Gujarat, and the ecosystem dynamics in this location, without the intent to compare ecosystems across different geographies.

\section{Figure 1. RTI's innovation ecosystem assessment (IEA) framework}

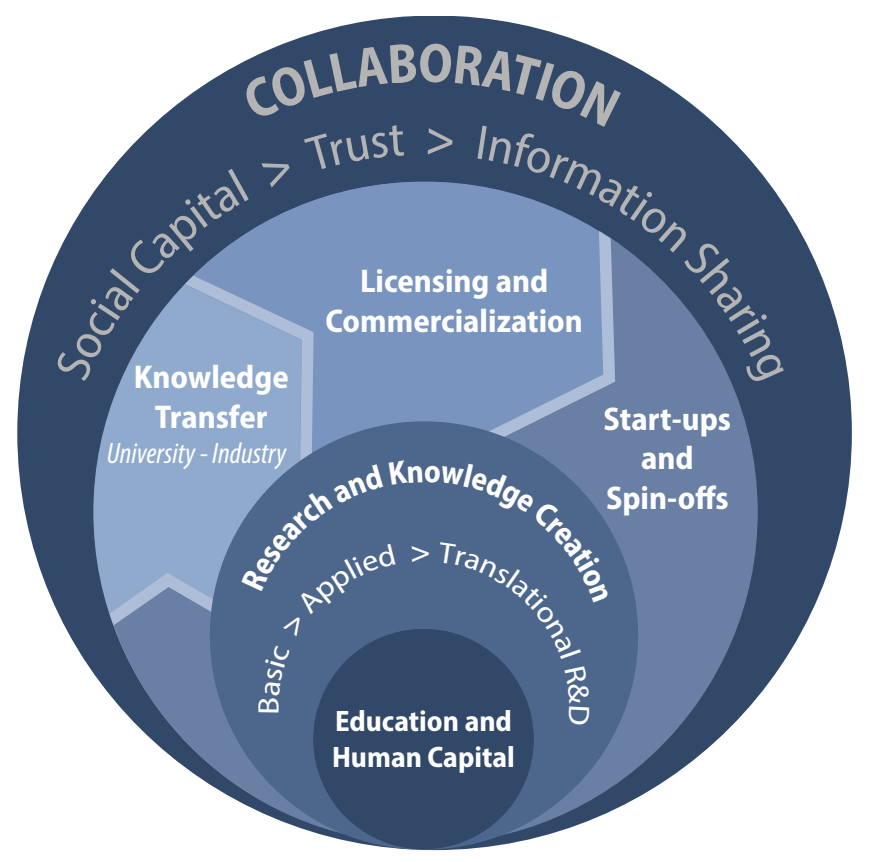

The RTI-developed framework highlights that an effective innovation ecosystem consists of several interrelated building blocks, which include elements of human capital, research and knowledge creation, knowledge transfer, IP, and a collaboration infrastructure. The framework draws upon US National Science Foundation (NSF) research on building a knowledge economy, and it applies the NSF's definition of an innovation ecosystem, which "models the economic rather than the energy dynamics of the complex relationships that are formed between actors or entities whose functional goal is to enable technology development and innovation."10 
Research and knowledge creation (both of which occur as basic, applied, and translational activities) stem from a strong core of education and human capital. For the ecosystem to function, new knowledge must be transferred into commercial applications. The paths to commercial use include (1) direct service agreements where universities provide direct assistance to commercial clients on discrete tasks, (2) commercialization through licensing where the IP rights are transferred to an outside organization for further development, and (3) spin-offs and start-ups that transition IP to small firms that typically include the research as part of organizational growth. Finally, the elements of the ecosystem function only in an atmosphere of collaboration, which is dependent on social capital, trust, and information sharing. Together, these elements make up the innovation ecosystem for a region.

With this framing, RTI reviewed market data on India and the State of Gujarat, followed by Gujarat-based research that employed a qualitative approach. RTI then gathered firsthand data by means of semistructured, in-person interviews to collect evidence and nuanced insight through interaction with a cross-section of stakeholders. Market research and networking contacts led to RTI conducting stakeholder interviews with more than 30 organizations in the urban economic hubs of Gandhinagar, Ahmedabad, Vadodara, and the surrounding areas. Organizations interviewed included a balance of stakeholders from leading universities; governments; noted start-up companies; reputed, large, private-sector entities; and several leading incubator and entrepreneurship development entities. RTI also participated in two leading innovation and R\&D-related networking workshop events to gather additional insights to further assess the ecosystem based on the described framework.

\section{Data Analysis}

RTI completed desk research on key indicators in Gujarat and a review of the literature on innovation in India and in Gujarat as a basis for understanding key drivers and challenges for innovation in Gujarat. RTI documented and assembled stakeholder interviews in an idea or mind map approach, then synthesized interviews within and across stakeholder group categories to evaluate trends and the interactions within stakeholder groups. RTI identified thematic findings through an inductive qualitative approach to inform research objectives and formulate summary observations and recommendations.

\section{Results}

Interviews with stakeholders across the Gujarat innovation ecosystem indicated five main themes that are having impacts on the development of a robust, knowledge-based economy.

\section{Theme 1: Challenges in Recruiting and Retaining Top Talent in Gujarat Are Hindering the Development of the Knowledge Economy}

Gujarat has a strong nucleus of universities in its leading cities of Ahmedabad, Gandhinagar, and Vadodara that attract students from across the country. The state is developing young talent in schools such as the Sardar Vallabhbhai National Institute of Technology (SVNIT), Surat; National Institute of Design (NID), Gandhinagar; Indian Institute of Technology, Gandhinagar (IITGN); Indian Institute of Management, Ahmedabad (IIMA); Center for Environmental Planning and Technology (CEPT) University, Ahmedabad; Pandit Deendayal Petroleum University (PDPU), Gandhinagar; and Gujarat University, Ahmedabad. Such strong centers of academic excellence are critical to the development of a strong innovation ecosystem serving to attract, train, and graduate top new talent. However, Gujarat is not able to retain the majority of this talent after graduation. Stakeholder interviewees consistently mentioned a "brain drain," highlighting the need to create an expanded set of jobs in the knowledge economy. Leading university and corporate-sector stakeholders also mentioned the difficulty in recruiting or retaining top talent in Gujarat because of the limited job opportunities for spouses, which indicate that the low number of knowledge-based economy jobs creates a challenge for recruiting dual-income professionals. Although Gujarat's large metropolitan cities are more livable than others in India, Gujarat's job market is smaller by comparison. The state's prohibition on alcohol was frequently cited in interviews as a deterrent to recruiting and retaining young professionals.

Industry and government have invested in developing exemplary institutions (e.g., NID and IIMA) that train future leaders for industry jobs in design and business, respectively. Emphasis, however, is placed on skills development, not necessarily on knowledge creation. Although skills are essential to the development of a strong ecosystem, top-quality research and knowledge transitioning to product creation are missing. Institutions such as Nirma University in Ahmedabad with its pharmaceutical and biotechnology programs and IITGN in Gandhinagar with its engineering and biomedical teams are young and are only beginning to build the credibility for applied research involving industry collaborations. In fact, despite investment by the government, the number of students training in technical fields such as energy and biotechnology 
remains relatively modest. Without a broader and deeper pipeline of technical talent, Gujarat will struggle to transition into a knowledge-based economy.

Theme 2: R\&D Activity in Gujarat Is Characterized as Focused on Incremental Progress or Small Process Improvements

Large companies spend very little on $R \& D$ and primarily focus on cost reductions and manufacturing process improvements rather than technology development or new product development. The fact may be more pronounced in Gujarat given the historical business culture of trading and small manufacturing business. Stakeholders reported that shortterm growth priorities crowd out longer term investment into innovation, and there is a bias toward a short-term, cost-based mind-set.

Many firms also seek technology infusion from international sources. The foremost orientation is to find quick and easy innovation because it is "easier" to buy a company, purchase new technology and equipment, or enter into licensing agreements than to build homegrown, new technologies. These practices perpetuate the value engineering of "Make in India" while undermining the ability to "Invent in India" and thereby deliver breakthrough products and technologies. ${ }^{11}$

As in many parts of high-growth India, Gujarat has remarkable S\&T talent and an emerging set of young entrepreneurs. It is also the home of several major corporate entities. Interviews confirm that corporate R\&D is low at only $1 \%$ to $2 \%$ of profits in many large enterprises. Government funds directed to brokering public-private partners to help de-risk investment and enable innovative technology breakthroughs are not successfully seeding market-oriented collaborations.

\section{Theme 3: A Focus on Short-Term Returns Drives out Risk-Taking in Long-} Term, Capital-Intensive Investments

Gujarat's success in building large, profitable manufacturing and trade businesses hinders investors' willingness to invest in capital-intensive, long-term opportunities. Historically, investment in manufacturing and trade has resulted in a quick return on investment, which has resulted in a small appetite for long-term, large-capital investment that is often required to support early stage, disruptive innovation. Interviewees report that there is little to no support for prototyping and prerevenue stage ventures. However, funding is more readily available for low-technology, short-turnaround ventures (e.g., information technology [IT] applications that do not require long-term investment), which may further drive entrepreneurial activity away from S\&T-heavy transformative innovation.
Entrepreneurship and innovation are important ingredients for economic growth. Gujarat is noted for its entrepreneurial culture. Robust corporate expansion in Gujarat has created public and private resources and high-net-worth individuals. A culture of venture investing or enhanced risk-taking to drive innovation is just beginning to take hold in the state.

Theme 4: Current Regulations and Bureaucratic Obstacles Hinder the Innovation Ecosystem

Entrepreneurial community interviews suggest a general frustration around starting and running a new business. Challenges such as tax requirements (e.g., customs and duty taxes), depreciation and loss recognition, banking practices, and labor codes are barriers for start-ups. ${ }^{12}$ Many interviewees also expressed administrative headaches in office and factory space leasing and indicated that utility permissions for new company locations were costly and time-consuming. Large enterprises also face challenges in how $R \& D$ investments are classified in the tax code, and tax review and approval for R\&D are slow. These views on barriers are consistent with global scorecards that place India low on the rankings for ease of doing business. ${ }^{3}$ These business barriers often diminish longterm innovation and serve to drive inventors to develop new technologies outside of the country, which in turn decreases India's global competitiveness.

Gujarati's state government has developed various initiatives to support businesses, including developing centers of excellence, forming and funding incubators to support start-ups, facilitating statewide forums like Vibrant Gujarat that bring members of industries together to encourage collaborations, and creating various funding schemes to encourage $R \& D$ activity. At the national level, the recently launched "Start-Up India, Stand Up India" program and start-up policy changes promote easier bank financing practices for entrepreneurs. Still, most interviewees reported either being unaware of the government resources or having a pessimistic view of publicsector resources and support.

Theme 5: Linkages for Applied Research among Stakeholders within the Innovation Ecosystem Are Weak

Leading higher education institutions, a broad and strong industrial base, and a business-oriented government create a backbone for Gujarat's innovation ecosystem. However, the innovation ecosystem lacks linkages across sectors or between actors.

Examples of industry-commissioned research at universities are limited. Also, seed funds from government with industry and academia tend to be small and short in duration, limiting long-term technology development processes. 
Stakeholder input suggested that university-based research is weak and undervalued by industry. Testing rigor and equipment inventory may not reflect best practices, and research more often is focused on pure science rather than applied or market-directed. Academia's applied research engagement with industry is low and thus not primed to help solve industry's problems.

Cross-disciplinary interaction that often fuels innovation is lacking in Gujarat. For example, its universities are focused on specific disciplines, such as business, design, engineering, or trade skills, and they lack multidisciplinary exchange that fosters cross-disciplinary innovation and problem solving that meets market needs. Although Gujarat's schools and colleges are beginning to collaborate across disciplinary boundaries, there is limited evidence of the type of interuniversity collaboration that produces exciting, new innovations. Interviewees indicated an interest in creating more collaborative projects across disciplines and the advancement of a "one-campus" structure to tackle business or societal issues and to facilitate the breakdown of these artificial boundaries across student and faculty researchers.

\section{Discussion}

Although Gujarat faces barriers to a robust innovation ecosystem, many of its necessary assets are in place. The key to future success will be addressing some of the current hurdles and enabling the nascent ecosystem to thrive. The glass is half full, and the future is bright.

The following five recommendations reflect a means for addressing the challenges identified in each of the aforementioned themes.

\section{Develop Industry Clusters}

Industry clusters provide a competitive advantage by acting as a vehicle for the economic development of industries, regions, and nations. Gujarat has started down this path, but can do more to deliberately develop industry clusters to build a stronger knowledge economy. Tight criteria for channeling investment to target sectors and geographies can build the innovation ecosystem in a sector and lead to job creation, which will help keep and attract talent in the state-a critical gap. A core thrust is to recognize and focus on the state's core strengths and invest in building on them. Energy, engineering materials, agriculture, pharmaceuticals, and biotechnology are a few of Gujarat's best assets, which serve as strong focus areas on which to build an engine for the knowledge economy, rather than trying to compete in the IT sector.
Efforts must include encouraging market-oriented university research to target themes, incentivizing corporate $R \& D$ and the development of high-technology smaller enterprises, and channeling talent into targeted geographic spaces to build a cross-pollinating culture and source of supply chains. Targeting growth sectors will support expanding the pie of job opportunities, which in turn works to address recruitment and retention challenges.

\section{Use Funding to Incentivize Application-Oriented R\&D}

Focus public research funding on industry-relevant technologies that will have an impact on and encourage a knowledge-based economy. Government initiatives should redirect funding schemes to incentivize universities and research institutes to pursue research that is market-oriented. The promotion of industry-matching programs to stimulate market-focused research and collaboration is a priority.

State S\&T policies could do more to nurture cofinancing schemes through public-private partnership requirements and longer funding durations because such programming has been shown to be successful in a number of countries where collaborations are strong and R\&D output is higher than in India. These schemes will serve the dual purpose of strengthening the funding landscape and foster connections across actors, which is another challenge the ecosystem faces.

\section{Cultivate the Funding Pipeline for S\&T-Based Start-ups and Product Development}

Gujarat's government and industry can do more to support capital-intensive, S\&T-based technology development. New product development and start-ups require longer time frames to iterate prototypes and require capital to sustain prototyping development cycles. Support could include providing longer term tax breaks and other incentive programs such as seed funding to assist with proof-of-concept, prototype infrastructure, and product development. One option is Innovation Vouchers, a UK policy innovation worth up to $£ 5,000$ that supports access to external experts who can help nascent entrepreneurs position their business for growth. ${ }^{13}$

In addition to support for the ventures themselves, riskmitigation assistance for early investors can help catalyze new investment activity. The UK's Seed Enterprise Investment Scheme (SEIS) is a tax break for investors who invest in qualifying companies that can return up to $78 \%$ investment the year the company starts trading. ${ }^{14}$ 
4. Eliminate or Reduce Barriers for Businesses and Improve Incentives for R\&D Investment

Gujarat is a noted progressive and pro-business state, but its firms still struggle to do business effectively and efficiently in the bureaucracy-laden context. India ranks low at 134th out of 189 economies in the 2015 World Bank "Ease of Doing Business" ranking and is plagued by issues of tax law opacity, customs, labor law, and firm registrations. ${ }^{15}$ Government at both the national and state levels must actively ease to eliminate these bottlenecks to make it easier to start a business and pursue innovation-related activities. Much can be done to further Gujarat's good efforts to simplify and automate building permits, clearances, and utility hookups. Efforts could also include incentivizing R\&D investment in larger firms by offering expanded tax considerations for depreciation and loss recognition, expediting the approval of $\mathrm{R} \& \mathrm{D}$ special tax considerations, and offering business capacity-building support for start-ups and small enterprises. Stakeholders also noted that prohibition policies are a hindrance to the recruitment and retention of young professionals in Gujarat.

The US and UK have some of the best examples of publicsector programs to seed private-sector R\&D. The US's Small Business Innovation Research (SBIR) and Small Business Technology Transfer (STTR) programs, as examples, provide capital to small businesses that are developing high-risk, high-return technologies and products and play a large role in overcoming the "valley of death," thereby de-risking a company's investment into innovation. In 2010, roughly $60 \%$ of seed capital in the US was funded through SBIR and STTR awards. ${ }^{16}$ The UK has been progressive in this area and offers a model to follow, including (1) R\&D tax credits that pay cash to companies that are doing innovative R\&D (up to $25 \%$ of R\&D spent can be refunded each year) ${ }^{17}$ and (2) Patent Box, which helps profitable companies get tax breaks up to $20 \%$ if they own European Union patents covering some aspect of their product. 18

\section{Foster Enhanced Collaboration among Stakeholders within the Ecosystem}

Key informant interviews indicated a lack of awareness about national and state programs to support innovation, suggesting a need for additional outreach and engagement by the public sector. More can be done to raise awareness of available government resources that promote market-facing research in Gujarat's universities and companies through a clear marketing and communication strategy and recognition via state news coverage to highlight successful examples.
Universities can encourage student and faculty research that is market-facing through more outreach to attract industrycommissioned research and facilitate student placements or industry placement at universities. More industry engagement with campus networking, internships, and staff exchanges are examples of low-cost steps to boost connections to shared interests and drive research to address industry and societal problems. The US, UK, and Singapore offer strong examples.

Expanding on initiatives to harness university-to-university collaboration will help promote multidisciplinary programs where Gujarat has real strength in higher education. For example, efforts to link the NID, IIMA, and IITGN in joint student programs hold promise. Sector targeting to prioritize funding and applied research to areas of greatest strength (e.g., energy, biotechnology, and robotics) also can be effective to grow clusters on the backs of professional networking and synergies.

\section{References}

1. Census.gov [Internet]. Washington, DC: US Census Bureau; 2009 Dec 15 [cited 2015 Sep 27]. China's population to peak at 1.4 billion around 2026: Census Bureau projects India to become most populous country in 2025 [CB09-191 news release]. Available from: https://www.census.gov/newsroom/ releases/archives/international_population/cb09-191.html.

2. Confederation of Indian Industry. Knowledge Economy [Internet quarterly newsletter, inaugural issue, $28 \mathrm{pp}$.]. 2015 Mar [cited 2016 May 11]. Available from: http://www. ciitechknow.com/innovation/pdf/Knowledge-EconomyBooklet.pdf.

3. Dutta S, Lanvin B, Wunsch-Vincent S, editors. The Global Innovation Index 2014: the human factor in innovation, 7th edition [Internet]. Fontainebleau, France; Ithaca, New York; and Geneva, Switzerland: INSEAD, Cornell University, and WIPO (World Intellectual Property Organization); 2014 [cited 2016 May 11]. Available from: https://www. globalinnovationindex.org/content/page/past-reports/.

4. Battelle and R\&D Magazine. 2014 global R\&D funding forecast [Internet]. Columbus, Ohio: Battelle; 2013 Dec [cited 2015 Oct 3]. Available from: http://www.battelle.org/ docs/tpp/2014_global_rd_funding_forecast.pdf.

5. Gupta A, Catalyst Management Services, Center for Education Innovations. Education status report-Gujarat: primary, middle, and secondary education [Internet working paper]. Washington, DC: Center for Education Innovations, Results for Development Institute; 2013 Oct [cited 2016 May 11]. Available from: http://www.educationinnovations. org/sites/default/files/Status\%20of\%20Elementary\%20 Education\%20in\%20Gujarat.pdf. 
6. Economist.com [Internet]. Going global: secrets of the world's best businesspeople. London, England: The Economist; 2015 Dec 19 [cited 2016 Jan 6, about 8 pp.]. Available from: http://www.economist.com/ news/christmas-specials/21683983-secrets-worlds-bestbusinesspeople-going-global.

7. StatisticsTimes.com [Internet]. Indian states by GDP [updated 2015 Aug 20; cited 2016 Mar 16]. Available from: http://statisticstimes.com/economy/gdp-of-indian-states. php.

8. Gujarat State Innovation Council, Industrial Extension Bureau. Vibrant Gujarat summit on innovation \& research development [Internet presentation, 42 slides]. Gandhingar, India: Gujarat State Innovation Council; 2014 Nov 10 [cited 2015 Sep 24]. Available from: http://www.slideshare.net/ vibrant_gujarat/vibrant-gujarat-summit-on-innovationresearch-development.

9. RTI International. Science, Technology, Research and Innovation Development (STRIDE): Philippines innovation ecosystem assessment [Internet, 39 pp.]. Research Triangle Park, NC: RTI International; 2014 Nov [cited 2016 May 11]. Available from: http://www.stride.org.ph/Data/ Attachments/548695c2d33d0505.pdf.

10.Jackson DJ. What is an innovation ecosystem? [Internet white paper, 13 pp.]. Arlington, VA: National Science Foundation; 2011 [cited 2015 Sep 27]. Available from: http://erc-assoc.org/content/what-innovation-ecosystem.

11.MakeinIndia.com [Internet]. New Delhi, India: Invest India, Federation House, Tansen Marg; 2015 [cited 2015 Sep 26]. Make in India home page [about 5 screens]. Available from: http://www.makeinindia.com/home.

12.Department of Science \& Technology, Ministry of Science \& Technology, Government of India. Stimulation of investment of private sector into research and development in India [Internet white paper, 66 pp.]. New Delhi, India: The Department; 2013 May [cited 2016 May 11]. Available from: http://www.slideshare.net/ ConfederationOfIndianIndustry/white-paper-final-18613.
13 Innovateuk.org [Internet]. Swindon, England: Innovate UK; 2016 [cited 2016 May 11]. Available from: https://vouchers. innovateuk.org/.

14.Seis.co.uk [Internet]. London, England: Seed Enterprise Investment Scheme (SEIS); 2016 [cited 2016 May 11]. Available from: http://www.seis.co.uk/.

15.The World Bank [Internet]. Washington, DC: The World Bank; 2016 [cited 2016 May 11]. Ease of doing business index (1=most business-friendly regulations) [about 12 screens]. Available at: http://data.worldbank.org/indicator/ IC.BUS.EASE.XQ/countries.

16.Ceulemans S, Kolls JK. Can the SBIR and STTR programs advance research goals? Nat Immunol. $2013 \mathrm{Feb}$ 15;14(3):192-195. http://dx.doi.org/10.1038/ni.2495.

17.Gov.uk [Internet]. London, England: HM Revenue \& Customs. Corporation tax: research and development tax relief; 2007 Jan 1 [cited 2016 May 11]. Available from: https://www.gov.uk/guidance/corporation-tax-researchand-development-rd-relief.

18.Gov.uk [Internet]. London, England: HM Revenue \& Customs. Corporation tax: the patent box; 2007 Jan 1 [cited 2016 May 11]. Available from: https://www.gov.uk/ guidance/corporation-tax-the-patent-box. 
Gujarat's Innovation Ecosystem

About the Authors

Myles F. Elledge, MA, is a senior director in RTI's Innovation Advisors group.

Jamie N. Jones, PhD, is a manager in RTI's Innovation Advisors group.

Moline Prak Pandiyan, MEMP, is an innovation and commercialization

manager in RTI's Innovation Advisors group.

\section{Acknowledgments}

This innovation ecosystem assessment was supported through RTI International's internal research and development funds. The authors acknowledge the tremendous contributions of time and insight from a range of public and private sector stakeholders in Gujarat.

RTI Press Research Briefs and Policy Briefs are scholarly essays on policy, methods, or other topics relevant to RTI areas of research or technical focus.

RTI International, 3040 East Cornwallis Road, PO Box 12194

Research Triangle Park, NC 27709-2194 USA

$919.541 .6000 \quad$ rtipress@rti.org www.rti.org

(02016 RTI International. All rights reserved. Credit must be provided to the author and source of the publication when the content is quoted. No part of this publication may be reproduced in any form by any electronic or mechanical means without permission in writing from the publisher. RTI International is a registered trademark and a trade name of Research Triangle Institute.

RTI Press publication RB-0012-1606

www.rti.org/rtipress 